\title{
Meios de provas no direito do trabalho
}

Means of proofing in labor law

Medios de prueba en derecho laboral

Preuve du droit du travail

\section{Diane Graciele Gaspar Soares}

\section{OpenEdition}

\section{Journals}

\section{Edição electrónica}

URL: http://journals.openedition.org/espacoeconomia/9062

DOI: 10.4000/espacoeconomia.9062

ISSN: 2317-7837

\section{Editora}

Núcleo de Pesquisa Espaço \& Economia

\section{Refêrencia eletrónica}

Diane Graciele Gaspar Soares, « Meios de provas no direito do trabalho », Espaço e Economia [Online], 16 | 2019, posto online no dia 30 dezembro 2019, consultado o 10 janeiro 2020. URL : http:// journals.openedition.org/espacoeconomia/9062 ; DOI : 10.4000/espacoeconomia.9062

Este documento foi criado de forma automática no dia 10 janeiro 2020.

(c) NUPEE 


\title{
Meios de provas no direito do trabalho
}

\author{
Means of proofing in labor law \\ Medios de prueba en derecho laboral \\ Preuve du droit du travail
}

Diane Graciele Gaspar Soares

\section{INTRODUÇÃO:}

1 Em tempos neoliberais a perspectiva de desregulamentação da legislação trabalhista assume a esmagadora atenuação da participação do Estado no mercado de trabalho. Em vista desse fato, o presente projeto é uma investigação interdisciplinar do Direito trabalhista numa perspectiva geográfica e dispõe-se a analisar a reforma trabalhista em curso atual no Brasil e o seu alcance na Educação. A discussão alusiva a essa matéria compreende dois grandes eixos: o impacto da reforma da legislação trabalhista na Educação, contextualizando a historicidade da prova como fato social , e a Geografia crítica fundamentada pela bibliografia de Milton Santos. Nesse sentido, foram analisadas a obra de Milton Santos, uma pesquisa empírica dos documentos, revistas e bibliografias que estudam a reforma trabalhista na Educação, e o parecer de implicação de pesquisa foi utilizado como metodologia nas análises.

2 Justamente por reconhecer a interdisciplinaridade que há no debate entre o Direito do Trabalho e a ciência geográfica, que esse projeto propõe-se a enfocá-lo no contexto da construção do espaço social. Em virtude da reforma trabalhista ter sido propagada como algo adequado e aprazível pelas mídias, torna-se importante essa discussão para tentar traduzir como ela reflete a popular flexibilização do trabalho em precarização da força de trabalho, em livre demissão, em terceirização e sub-contratação, em rotatividade da força de trabalho, bem como analisar como essa desregulação das normas do trabalho implica em reestruturação da relação entre o capitalismo e o trabalho, seus efeitos profundos no envolvimento dos agentes do conhecimento da 
Educação no Brasil na sua instituição. Em conformidade com Santos (1996): "a noção de intencionalidade [...] é igualmente eficaz na contemplação do processo de produção e de produção das coisas, considerados como um resultado da relação entre o homem e o mundo, entre o homem e o seu entorno." (SANTOS, 1996, p.58). o geógrafo explica que a progressiva especialização dos lugares notabiliza a divisão do trabalho.

3 A Geografia crítica iniciada em 1960 com princípios marxistas ganha alcance global através das contribuições e estudos de Milton Santos, ela advoga para si como interpretar o espaço por meio do materialismo, histórico e dialético, como entender o cerne social nas relações geográficas do espaço. Nesse contexto contemporâneo de reestruturação econômica produtiva, faz-se indispensável para essa análise das transformações das relações de trabalho e como se expressam na desregulamentação das leis trabalhistas no Brasil, especialmente com os agentes de conhecimento na Educação. Refletir em como esses agentes do conhecimento vão se adequar a essa reforma trabalhista, a essa reestruturação da força de trabalho na Educação, que significa a sobrevivência dentro de procedimentos da organização do trabalho, como a adoção de multifuncionalidades. Segundo Santos (1996): "com a marcha do capitalismo, amplia-se a tendência a que, sobre a diversificação da natureza, operada pelas forças naturais, se realize uma outra diversificação, também à escala global, mediante forças sociais." (SANTOS, 1996, p. 85). O autor explica que a divisão territorial do trabalho promove uma hierarquia dos lugares e fragmenta a totalidade das capacidades. Em como a intermitência e periodicidade histórica alteram a divisão do trabalho.

Essa pesquisa utilizou-se da obra de Milton Santos porque reconhece que a Geografia crítica tem significado no atual neoliberalismo, que a obra de Milton Santos tem alcance e abrangência que permeiam as ações e estratégias do capitalismo do norte ao sul, realça a observação das consequências da Reforma Trabalhista para a força de trabalho na Educação até perscrutar o próprio espaço como campo de lutas, demarcado em classes. Esse debate sinaliza que tais mudanças de atenuação da participação do Estado nesse espaço de lutas não são para reestruturação, discussão e busca de soluções dos conflitos para a força de trabalho, mas um conjunto de medidas que claramente propendem para uma desregulamentação de direitos, flexibilização das relações de trabalho e descrédito da representação sindical. Segundo Santos (1996): "a divisão internacional do trabalho é processo cujo resultado é a divisão territorial do trabalho. Sem dúvida, as duas situações se aparentam, embora mude a energia que as move. Por outro lado, a natureza é um processo repetitivo, enquanto a divisão do trabalho é um processo progressivo." (SANTOS, 1996, p.86). O geógrafo elucida que no mundo globalizado, a inovação e os meios informacionais direcionam a Divisão Internacional do Trabalho, bem como especificam as deliberações, propósitos e a finalidade do setor financeiro.

5 Essa pesquisa teve como inspiração a releitura de Milton Santos, e buscou esclarecer os princípios que estabelecem a atenuação da participação do Estado no mercado de trabalho, e suas implicações na Reforma Trabalhista, observando a Legislação Trabalhista no Brasil e os teóricos que tratam dessa reflexão na Educação como (SANTOS, 1978; SANTOS, 1996; SANTOS, 2013 ; SILVA, 2016; DAMIANI, 2008; BAITZ, 2006 ; HARVEY, 2005, dentre outros). É necessário ressaltar que essa pesquisa bibliográfica permitirá analisar a Geografia crítica no Direito do Trabalho conforme o pensamento, a abordagem metodológica, conceitual, o plano epistemológico, cultural, e que refletirá o 
olhar de cada autor e sua perspectiva sobre o mundo do trabalho contemporâneo, tornando esse exercício desafiador e instigante.

6 Como problemática central essa pesquisa investigou quais são os fatores presentes na Reforma Trabalhista atual que pretendem: restringir, condensar, ou realmente suprimir direitos trabalhistas com delineamentos manifestamente neoliberais na Educação Superior?

\section{METODOLOGIA E DESENVOLVIMENTO:}

7 Observa-se que o procedimento de auferir, de armazenar, de categorizar e divulgar informações de uma pesquisa acompanha o rápido progresso dos novos talentos, técnicas e critérios de análise de dados. O presente trabalho foi uma pesquisa qualitativa, que utilizou a implicação de pesquisa como metodologia nas análises, a abordagem da Geografia crítica para essa pesquisa privilegiou as concepções e ideias compreendidas nas obras Por uma Geografia Nova: Da Crítica da Geografia a uma Geografia Crítica, publicada em 1978 e A natureza do Espaço: Técnica e Tempo, Razão e Emoção, publicada em 1996. Não obstante essa proposta de trabalho jamais se limitou apenas a essas duas bibliografias. Além dessa pesquisa bibliográfica, essa trabalho necessitou de uma pesquisa empírica baseada em todos os documentos que tratam da Reforma Trabalhista, desde 1994, implementada pelo governo de FHC até a proposta atual, isso incluí todos os documentos, publicações, projetos de Lei pelo Executivo e Legislativo, e medidas legais aprovadas, visto que é um marco das ações das políticas neoliberais na Educação no Brasil.

vista dos argumentos mencionados, esse trabalho necessitou ainda da interpretação da Reforma Trabalhista considerando a historicidade da prova como fato social, e essa interpretação não é uma reflexão do Direito do Trabalho exclusiva das normas da CLT, nessa sistemática de relações do trabalho é indispensável ouvir a voz dos agentes de conhecimento, e portanto, como já foi apresentada a relevância das fontes bibliográficas para esse trabalho.

9 Para compreensão teórica, estabeleceram-se aqui os conceitos de metodologia de implicação de pesquisa, de Geografia crítica e de território em conformidade com os seguintes expertos: Baitz (2006): “É assim que a implicação se põe. Essa palavra-valise significa, em primeira análise, que o pesquisador capaz de examinar um objeto através da separação sujeito objeto pode agora aproximar-se e incluir-se na jornada de pesquisa." (BAITZ, 2006, p.31). Já Santos (1978) afirma que a Geografia crítica necessita interpretar o espaço como: "o espaço organizado pelo homem é como as demais estruturas sociais, uma estrutura subordinada-subordinante. É como as outras instâncias, o espaço, embora submetido à lei da totalidade, dispõe de uma certa autonomia." (SANTOS, 1978, p. 145). Para Haesbart (2007): "Território, assim, em qualquer acepção, tem a ver com poder, mas não apenas ao tradicional "poder político". Ele diz respeito tanto ao poder no sentido de dominação, quanto ao poder no sentido mais implícito ou simbólico, de apropriação." (HAESBART, 2007, p.20).

Após estas etapas de revisão e investigação, os resultados obtidos foram organizados de modo a oferecer características importantes para a escolha dos fatores presentes na Reforma Trabalhista atual que pretendem restringir, condensar, ou realmente suprimir direitos trabalhistas, além de dialogar com os profusos agentes sociais abrangidos 
(Estado, capital e trabalho), e expor como essas concepções de reforma adquirem delineamentos manifestamente neoliberais na Educação Superior.

11 Inicialmente, para a realização desse trabalho foi necessário o entendimento de que a produção de provas é o meio disponível que as partes encontram para demonstrar ao juízo a veracidade dos fatos alegados que pretendem comprovar. Contudo, as provas fundamentam e influenciam o convencimento do juízo.

Temos no Novo Código do Processo Civil, que é uma fonte subsidiária aplicada ao processo do trabalho, em seu artigo 369 que " as partes têm o direito de empregar todos os meios de legais, bem como os moralmente legítimos, ainda que não especificados neste Código, para provar a verdade os fatos em que se funda o pedido ou a defesa e influir eficazmente na conviç̧ão do juiz". Também não podemos deixar de citar a importância do objeto da prova que deve estar intimamente ligado aos fatos alegados, aos fatos controvertidos e aos fatos relevantes evidenciado na lide, a fim de solucionar o deslinde processual.

13 Em progressão, o presente estudo buscou analisar o contexto da Reforma Trabalhista abordando o ônus da prova. Nesse sentido, o atual texto da CLT diz que a prova incumbe a parte que as fizer, ou seja, a prova cabe a quem alega, nesse sentido causando uma insegurança jurídica, uma vez que existe uma defasagem nesse texto da década de 1940, quando então surgiu a CLT.

14 Com a reforma trabalhista, a regra geral não mudou, ou seja, o ônus da prova caberá a quem alega, conforme prevê o art. 818 da CLT. Contudo, a letra deverá se apresentar de forma mais atual e em sintonia com a fonte de lei utilizada de forma subsidiaria na justiça do trabalho, ou seja, em sintonia com Novo Código do Processo Civil.

15 Sendo assim, diante de tantas peculiaridades em relação a prova ou diante da dificuldade de provar ou ainda diante da maior facilidade de se ter a provado fato, poderá o juiz direcionar o ônus da prova de modo diverso, conforme estabelece o art. 818, parágrafo $1^{\circ} \mathrm{da}$ CLT, assim abaixo:

"Nos casos previstos em lei ou diante de peculiariedades da causa relacionadas a impossibilidade ou a excessiva dificuldade de cumprir no encargo nos termos deste artigo ou a maior facilidade de obtenção da prova do fato contrario, poderá o juízo atribuir no ônus da proa de modo diverso, desde que o faça por decisão fundamentada, caso e que deverá dar a parte a oportunidade de se desincumbir do ônus que lhe foi atribuído."

16 No entanto, esse redirecionamento da prova deverá acontecer antes da abertura da instrução processual, a requerimento da parte, o que causará o adiamento da audiência de instrução, o que possibilitará provar os fatos por todos os meios admitidos em lei, conforme art. 812, parágrafo $2^{\circ}$ da CLT, abaixo:

“A decisão referida no $\$ 1^{\circ}$ deste artigo deverá ser proferida antes da abertura da instrução e, a requerimento da parte, implicará o adiamento da audiência e possibilitará provar os fatos por qualquer meio em direito admitido."

17 Deve se ter em mente, em se tratando da Justiça do Trabalho, o entendimento majoritário é que o ônus da prova em muitas das matérias relacionadas a lide é da empresa e não do empregado, principalmente em casos que os assuntos já estão simulados, como por exemplo horas extras e recolhimento do FGTS.

Nesse sentido, o presente trabalho reforça a importância de esclarecimento e caracterização dos meios de provas na Reforma Trabalhista. As provas documentais, no processo trabalhista estão amparadas na Consolidação das Leis Trabalhistas (CLT) em 
seus artigos 777, 780, 787, 830 e quando necessário, aplica-se subsidiariamente o Novo Código de Processo civil (NCPC). Dessa forma, nos ensinam Saraiva e Manfredini que "documento é o meio idôneo utilizado como prova material da existência de um fato, abrangendo não só os escritos, mas também os gráficos, as fotografias, os desenhos, reproduções cinematográficas, etc".

Documento possui duas definições. Segundo uma visão mais ampla, documento é tudo aquilo de que se pode extrair a existência de um fato. Enquanto isso, em uma visão mais restrita, documento pode ser entendido como o escrito, ou melhor, a expressão gráfica de um determinado fato. No processo do trabalho, são aceitos documentos em seu sentido amplo, valendo como documentos eventuais fotografias, desenhos, entre outros.

De acordo com o art. 830 da CLT, o documento apresentado em juízo como prova só poderá ser aceito se apresentado em sua versão original, em certidão autêntica ou cópia autenticada, a qual poderá ser verificada perante o juiz ou o tribunal no qual a prova foi apresentada. Vejamos a redação do mencionado artigo:

- Art. 830 - O documento oferecido para prova só será aceito se estiver no original ou em certidão autêntica, ou quando conferida a respectiva pública-forma ou cópia perante o juiz ou Tribunal.

$21 \mathrm{Na}$ justiça do trabalho as cópias de provas apresentadas, serão autenticadas pelo advogado, sob sua responsabilidade, conforme estabelece a CLT, no art. 830, somente será apresentado os originais quando necessário a parte que o pediu. Assim descreve Martins: [...] a parte que a produziu será intimada para apresentar cópias devidamente autenticadas ou original, cabendo o serventuário competente proceder à conferência e certificar a conformidade entre esses documentos.

o juiz poderá determinar que a parte exiba documento ou coisa em juízo, desde que se ache em seu poder. Deve haver um requerimento de que a parte tenha o documento e que ele deva ser juntado. Se não houver juntado, há presunção relativa daquilo que se pretendia provar por intermédio desse documento.

Podemos produzir diversas provas através de documentos escritos. Podemos citar como exemplo o artigo 464 da CLT que diz que a comprovação do salário só pode ser através de proa documental, através de recibo ou comprovante de pagamento, não sendo aceito pelo juízo prova testemunhal para comprovação de pagamento de salário.

Como considerações gerais sobre os documentos no processo do trabalho, são destacáveis fatos como o disposto no art. 456 da CLT, que dispõe que a prova do contrato individual do trabalho será feita por meio das anotações constantes da carteira profissional ou por instrumento escrito, e suprida por todos os meios permitidos em direito.

- Art. 456. A prova do contrato individual do trabalho será feita pelas anotações constantes da carteira profissional ou por instrumento escrito, e suprida por todos os meios permitidos em direito.

- Parágrafo único. A falta de prova ou inexistindo cláusula expressa e tal respeito, entenderse-á que o empregado se obrigou a todo e qualquer serviço compatível com a sua condição pessoal.

Outro ponto importante, é o caso do registro de entrada e saída de funcionários que deve ser registrado de maneira manual, mecânica ou eletrônica, conforme art. 74, parágrafo $2^{\circ} \mathrm{da}$ CLT. 
26 A parte reclamante em o prazo de 10 dias para impugnar os documentos apresentados, conforme determina ao artigo 411 do Novo Código do Processo civil.

A Súmula 8 do TST admite a apresentação de documentos novos ou supervenientes à sentença, quando comprovado o justo impedimento para sua apresentação ou quando se referir a fato posterior à sentença.

$\mathrm{O}$ incidente de falsidade pode ser suscitado a qualquer momento. Na contestação ou no prazo de 10 dias após a juntada do documento. Nesse caso, o processo fica suspenso para decisão, que verificará a necessidade de perícia técnica. A sentença irá decidir $\mathrm{s}$ obre incidente de falsidade, se será declaratória, e confirmando a falsidade ou autenticidade do documento, não caberá recurso, por se tratar de uma decisão interlocutória.

29 As provas emprestadas são admitidas no direito do trabalho e tem seu amparo nos princípios instrumentalistas das formas e da economia e celeridade processual, contudo, o seu uso deve ser pautado nos princípios do contraditórios e da ampla defesa, da legalidade e da proibição das provas ilícitas.

30 Assim, temos que a evolução da história nos leva a uma gradual e irreversível independência do direito processual em relação ao direito material, dessa forma concluímos que o processo do trabalho busca a prestação jurisdicional de forma eficaz.

31 Ainda nesse raciocínio, o processo do trabalho não busca a mera prestação jurisdicional, sendo assim, o objetivo principal é a solução justa e eficaz do conflito de interesses.

32 O processo do trabalho busca uma ampla gama de meios de provas que podemos observar no art. 369 do Novo Código do processo Civil, dando margem ao aproveitamento não só de provas produzidas na relação processual, mas também a outro meio de prova produzida de forma lícita, denominada prova emprestada.

Dessa forma temos que a prova emprestada é o meio de convicção que se disponibiliza as partes do processo, tendo como fundamento os princípios da instrumentalidade das formas e da economia processual.

34 Ainda assim, a utilização de prova emprestada encontra muita resistência jurídica em nosso ordenamento jurídico. A jurisprudência trabalhista entende pela admissibilidade da prova emprestada em caso que exista contemporaneidade na prestação do serviço, e nos casos que seja oportuno o contraditório, dessa forma, poderá a parte contraria se manifestar em relação a prova produzida nos autos.

35 Podemos citar como exemplo atual na justiça do trabalho, a utilização como prova em prestada prova pericial emprestada nos casos em que ocorra a desativação ou o desaparecimento do local de trabalho.

36 Nesse caso, podemos observar a redação da OJ 278 da SDI-1 do TST, que estabelece que “a realização de perícia é obrigatória para verificação de insalubridade. Quando não for possível sua realização, como de fechamento da empresa, poderá o julgador utilizar-se de outros meios de prova".

37 Dessa forma, temos que a utilização de prova emprestada na justiça do trabalho, encontra-se perfeitamente aceitável, bem como pode ser utilizada em outros ramos do direito. Contudo, a sua utilização deve sempre atender aos princípios constitucionais da ampla defesa e do contraditório. 
38 A prova pericial na justiça do trabalho poderá ser requerida pela parte ou determinada pelo juiz, quando este achar necessário que uma determinada prova seja avaliada por perito, detentor de conhecimento técnicos e científicos sobre o caso, conforme estabelece ao art. 464 do NCPC.

Os artigos 826 e 827 tratam da prova pericial na justiça do trabalho, enquanto o art. 769 do texto consolidado dispões que "Nos casos omissos, o Direto Processual comum será a fonte subsidiaria do Direito processual do Trabalho, exceto naquilo em que for incomparável com as normas" do Título X da CLT que trata justamente do processo judiciário do trabalho.

Em que pese o artigo 765 da CLT conferir ampla liberdade ao magistrado na direção do processo, assim como o art. 130 do NCPC ao atribuir o poder deferir as provas pertinentes, isso não significa que o juiz pode, uma vez deferida a perícia, produzi-la a qualquer tempo e de qualquer forma, principalmente aos a prova oral, uma vez que é muito difícil, senão impossível, considerar com antecedência a primazia de um tipo de prova, porque valorizar um segmento das expectativas probatórias seria como se estivesse ocorrendo um pré-julgamento, o que é inadmissível.

41 Sendo assim, porque o Novo Código de Processo Civil estabelece uma diretriz sobre a oportunidade de primeiro se realizar a prova pericial, onde nesse aso a consolidação das Leis Trabalhista foi omissa, ao se realizar a prova oral e depois se ordenar a prova pericial, como alguns magistrados fazem, observamos assim uma inversão de valores.

o processo do trabalho, segue uma sequência lógica e não se permite que se modifiquem as fases probatórias, salvo por uma razão excepcional capaz de justificar os depoimentos antes da prova pericial.

43 Outrossim, configurasse verdadeira ofensa ao princípio do contraditório e da ampla defesa a impossibilidade de oitiva de testemunhas, e do próprio perito, após a conclusão do laudo.

44 A CLT em seu art. 826, garante as partes apresentar seu perito ou seu assistente técnico, essa medida é para que não haja divergências de provas, para que não haja confusão, dificultando a resolução da lide. Dessa forma, evita que haja parcialidade na produção de provas.

45 Os peritos devem figurar como agentes do Estado, conforme descreve Leite (2015):

"Quando se tratar de exame que tenha por objeto autenticidade ou falsidade de documento (v.g., exame grafotécnico), bem como matéria de natureza médico-legal, a escolha do perito deverá recair preferencialmente entre os servidores público que exerçam os correspondentes cargos técnicos nos órgãos da Administração Pública." (LEITE, 2015, p.75).

As partes podem comparecer à diligência em relação ao qual será feita a perícia. Esse comparecimento serve como espécie de esclarecimentos quando ao local de trabalho, etc.

O perito poderá ouvi as partes, mas não poderá se investir da condição de juiz para ouvir testemunhas. Ele pode orientar com as informações prestadas pelas pessoas, mas as testemunhas continuarão a serem ouvidas pelo juiz.

o juiz pode entender que não existe a necessidade produção de prova pericial ou que a produção da mesma será impossível, até mesmo quando o elemento comprobatório for nítido, não se fazendo necessário o conhecimento técnico. Dessa forma, poderá o juiz indeferir o pedido da perícia, conforme artigo 464, inciso II do Novo Código do Processo Civil. 
49 A testemunha é terceiro a o processo que é detentor dos conhecimentos dos fatos alegados. A Consolidação das Leis Trabalhistas não tem regras específicas em relação a testemunha, assim usa como fonte subsidiaria o Novo Código de Processo Civil.

A inquirição das testemunhas deve obedecer o disposto no art. 828 da CLT, no qual toda testemunha, prestará o compromisso legal de dizer a verdade, sob pena das leis penais, mas antes do compromisso, a parte contrária poderá arguir a contradita da testemunha, que significa alegar lhe a incapacidade, impedimento ou suspeição, o que poderá ou não ser deferido pelo juiz.

51 Por ser um dos meios de prova indispensável na Justiça do Trabalho, no nosso caso hipotético, as testemunhas trazidas por José Fulano e a Construtora que trabalhou, tiveram a responsabilidade de depor a verdade dos fatos que tem conhecimento, sendo assim, de certa forma, consideradas um terceiro na lide a auxiliar o juiz no seu convencimento dos fatos apresentados nos autos, na inicial e em defesa, pois o direito do trabalho busca a primazia da realidade, para apuração da verdade, independentemente da existência de eventual prova documental nos autos.

Neste momento, o juiz teve que ter uma psicologia e bom senso apurados para poder identificar a verdade no meio do depoimento prestado pelas testemunhas, isso face o risco da prova testemunhal, que na maioria dos casos pode vir cheia de má fé e distorção da verdade para beneficiar a parte que lhe indicou no processo.

53 No caso de José Fulano, ele e a empresa (autor e Réu) levaram suas testemunhas, Autor para provar o vínculo de emprego anterior à anotação de sua CTPS e diferenças das horas extras prestadas e não pagas; Já o Réu, contestou, com a alegação da não existência de trabalho em período anterior à anotação e jornada laboral extraordinária, além daquela consignada nos controles de ponto apresentados nos autos. Juntou documentos apenas do período com anotação e cartões de ponto britânicos.

Diante das alegações das partes, ambas apresentaram suas testemunhas e no decorrer da instrução ocorreu contradição nos depoimentos. As testemunhas do Autor confirmaram o vínculo no período sem anotação e, ainda, confirmou a prestação de serviço além da jornada anotada nos cartões de ponto. Já as testemunhas da empresa declararam que José Fulano nunca trabalhou na Construtora em data anterior àquela anotada em sua CTPS e que não trabalhava além do horário consignado em seus cartões de ponto.

Facultado ao Juiz, o mesmo realizou acareação, colocando as testemunhas frente a frente, com o objetivo de esclarecer os pontos divergentes nos depoimentos prestados e que acabaram controvertidos.

Como normalmente acontece, o Juiz do nosso caso, antes do fim da instrução, deu oportunidade às testemunhas de se retratarem, falando a verdade dos fatos que realmente presenciaram e conhecem. No entanto, apesar do nervosismo, não houve retratação de nenhuma das testemunhas das partes. Assim, as testemunhas foram alertadas de que deverão prestar depoimentos à Polícia Federal, que nos termos do art. $8^{\circ}$, VIII, letra c, da Constituição Federal, é a competente para apurar o ocorrido no processo trabalhista interposto por José Fulano

Nesta fase policial, as testemunhas serão novamente ouvidas, podendo ou não alterar seus depoimentos e, sendo constatada a disparidade entre os depoimentos, ficando claro que falsearam a verdade, o juízo trabalhista poderá determinar a expedição de comunicação ao Ministério Público Federal para apuração da existência de crime. 

que não serão admitidas:

Art. 228. Não podem ser admitidos como testemunhas:

I - os menores de dezesseis anos;

II - aqueles que por infermidade ou retardamento mental, não tiverem discernimento para a prática dos atos civil;

III - os cegos e surdo, quando a ciência do fato que se quer provar dependa dos sentidos que lhe faltam;

IV - o interessado no litígio, o amigo íntimo ou o inimigo capital das partes;

$\mathrm{V}$ - os cônjuges, os ascendentes, os descendentes e os colaterais, até o terceiro grau de alguma das partes, por consanguinidade, ou afinidade.

Parágrafo Único: para a prova de fatos que só elas conheçam, pode o juiz admitir o depoimento a que se refere este artigo.

$\mathrm{O}$ art. 829 da CLT estabelece que o testemunho de parente até o terceiro grau civil, amigo íntimo ou inimigo de qualquer das partes não tem eficácia, o seu depoimento valerá como simples informação, conforme abaixo:

- Art. 829 da CLT - A testemunha que for parente até o terceiro grau civil, amigo íntimo ou inimigo de qualquer das partes, não prestará compromisso, e seu depoimento valerá como simples informação."

O ilustre Martins nos diz que, "testemunha é um terceiro em relação a lide que vem prestar depoimento em juízo, por ter conhecimento dos fatos narrados pelas partes".

A prova testemunha embora seja uma prova frágil na justiça do trabalho, é a mais usada, visto que muitas das vezes é a única maneira do reclamante fazer provas de suas alegações. Isso ocorre, porque os mesmos não têm acesso aos documentos que na maioria das vezes fica em posse da empresa.

67 Tendo em vista o que foi debatido e fundamentando-se nas normatizações da CLT para a consideração de meio de provas no Direito do Trabalho, entende-se que a produção de provas no cotidiano e espaço laboral, em especial na Educação, sofreu alteridades políticas e econômicas pelo decurso da sociedade brasileira. Os meios de provas transcorreram como fatos sociais, e sua caracterização sofreu com a flexibilização do trabalho e todas as alterações laborais e de produção exigidas pela ideologia neoliberal, muito além da relevante manifestação do Estado e dos setores empresariais sobre a reestruturação e reforma do sistema educacional que prioriza uma economia competitiva, essa flexibilização do trabalho na educação se justifica pelos setores empresariais como desenvolvimento econômico, maior acesso e investimento para 
educação profissionalizante, em detrimento de uma ciência cidadã, de uma Educação como direito social que deve ser garantido pelo Estado, e de permitir a universalidade da Educação. Nesse contexto, o profissional da Educação suporta a Reforma trabalhista desde o governo FHC, já que a flexibilização do trabalho fomentou descaracterizações de funções laborais, dificultando, confundindo e tolhendo os meios de provas do exercício do trabalho educacional, essa sendo mais sensível na Educação, pois as reflexões e raciocínios dos setores empresariais para a Educação fundamentam-se em análises comuns aos Bancos para a concepção de desenvolvimento econômico, e o governo FHC é um marco das consequências da flexibilização do trabalho e da política educacional que fomenta a formação profissionalizante, que foram incorporadas pelo governo brasileiro. Segundo Santos (1996): "a ação humana tanto depende do trabalho vivo como do trabalho morto. 0 trabalho morto, na forma de meio ambiente construído (built environtnent) tem um papel fundamental na repartição do trabalho vivo." (SANTOS,1996, p. 91). O geógrafo esclarece que o cotidiano laboral, suas caracterizações, suas funções, seu território é composto e constituído pelo trabalho vivo e pelo trabalho morto, abrangendo questões subjetivas o que concerne a atividade do trabalho, que sofre mudanças histórico-econômicas quando pensadas como meio de provas no Direito do Trabalho.

Esse debate sobre a Reforma Trabalhista não se limita ao momento, nem as circunstâncias atuais, ele ainda sofrerá muita oposição, relutância e resistência da classe operária por muitos anos. A lógica do capital não assegura a força de trabalho proteção em caso de demissão, ou menor competitividade de produção para determinar a renda salarial. Além disso, a força de trabalho acredita na legislação trabalhista como proteção ao Direito do Trabalho, mas o neoliberalismo considera que a desregulamentação de direitos fomenta a geração de emprego e renda. Segundo Foucault (2008): "comportamentos que fazem que cada um dos indivíduos funcione como membro, como elemento dessa coisa que se quer administrar da melhor maneira possível, a saber, a população. Eles agem como membros da população devem agir." (FOUCAULT, 2008, p.57). 0 autor esclarece que há uma relação de poder explícita entre a instituição e a força de trabalho, entretanto a sua abrangência ganha formas requintadas de disciplina, de maneira específica no corpo humano, como modelar além de suas crenças, os movimentos, trejeitos, gestos e atitudes do próprio corpo.

De acordo com o que foi dito, a Geografia crítica faz uma reflexão pormenorizada sobre a colossal divergência de patamares entre instituição patronal e organização da força de trabalho, como os agentes (Estado, capital, força de trabalho) se edificam inseridos, nesse espaço social de luta, tanto na legislação trabalhista como na legislação sindical. Nesse contexto, analisar a Reforma Trabalhista atual sobre o olhar da Geografia crítica possibilita debater sobre esse espaço social de luta algumas prerrogativas do neoliberalismo de criar mecanismos de flexibilização de normas e regras que orientam, gerenciam e regem as relações da força de trabalho, e as suas consequências e efeitos na Educação Superior. De acordo com Santos (1996): “a formação socioespacial e não o modo de produção constitui o instrumento adequado para entender a história e o presente de um país. Cada atividade é uma manifestação do fenómeno social total. E o seu efetivo valor somente é dado pelo lugar em que se manifesta, juntamente com outras atividades." (SANTOS,1996, p.86). O geógrafo esclarece que o espaço social de luta da força trabalhista não é meramente um reflexo da sociedade, que esse espaço social abrange e se caracteriza como fator social, produto histórico, instância da sociedade. Como teatro das relações sociais de produção, esse espaço de produção 
regido pelo capital tem uma conotação ativa e de ritmos distintos ora produto, ora produtor, ora determinante, ora determinado pelas relações sociais construídas pela força de trabalho.

70 Em vista do que foi mencionado, esse estudo reflete sobre como a força de trabalho acredita na legislação trabalhista como proteção ao Direito do Trabalho, mas o neoliberalismo considera que a desregulamentação de direitos fomenta a geração de emprego e renda, por isso a necessidade da Geografia crítica para explicar o contexto atual da Reforma Trabalhista, em especial as suas consequências e efeitos na Educação Superior.

\section{RESULTADOS E CONCLUSÕES:}

71 Conclui-se parcialmente com este trabalho a identificação dos meios de provas e suas peculiariedades e generalidades. Dessa forma, nos utilizamos de preceitos contidos na CLT na aplicação de forma subsidiaria do Novo Código do processo Civil. Assim, foi possível relatar a forma de produção de prova e a sua valoração na justiça do trabalho especificamente.

Com a apresentação desse trabalho conhecemos o conceito de provas, os seus princípios, bem como a diferenciação das presunções jurídicas, que podem ser relativas e absolutas.

Do mesmo modo, apresentamos exemplos para aplicação dessas presunções jurídicas na justiça do trabalho.

74 Com relação a valoração dos meios de provas, temos que o magistrado deve se nortear sobre as provas constante no processo, podendo se valer do princípio do livre convencimento motivado, e da persuasão racional.

75 Contudo, o magistrado diante de dúvidas quanto a análise das provas, não poderá aplicar o princípio $n$ dúbio por operário, devera o magistrado proceder o julgamento contrário a parte detentora do ônus da prova.

Quanto a classificação dos meios de provas admitidos na justiça do trabalho, este se mostrou eficaz e esclarecedora, assim as principais provas utilizadas na justiça do trabalho são prova documental, prova testemunhal e prova pericial.

Em relação a admissibilidade da prova emprestada na justiça do trabalho e a forma como é procedida a sua utilização na justiça do trabalho, o presente trabalho se pautou em mostrar que a sua utilização é sempre pautada na celeridade e economia processual, atendendo obrigatoriamente os princípios constitucionais da ampla defesa e do contraditório.

No que tange ao ônus da prova com a vigência da reforma trabalhista, este trabalho demonstrou que, a regra geral, está fundamentada quando da criação das leis trabalhista em 1940, esta permanece, contudo, diante das especificidades, e da dificuldade que as vezes a parte tem em se comprovar o seu alegado, o ônus da prova deverá estar em sintonia com a fonte subsidiaria da justiça do trabalho que é o Novo Código do Processo Civil, bem como, deverá se apresentar de forma mais atual.

79 Assim, conclui-se que o trabalho realizado em relação aos meios de provas admitidos e na justiça do trabalho, conseguiu demonstrar o seu conceito, a sua utilização, as 
consequências de sua utilização de forma errada, como se desenvolve a instrução probatória no âmbito da justiça do trabalho, e as suas generalidades e peculiaridades.

O exercício de descrever a prova como fato social, sua história, suas tendências, seus sentidos, permitiu também observar que essa Reforma Trabalhista pelo modelo capitalista alcança o movimento sindical, em especial o sindicato dos professores e o desmantelamento da força de trabalho na Educação. E a necessidade de análise posterior dessas questões. Assim, o trabalho realizado em relação aos meios de provas admitidos e na justiça do trabalho, conseguiu demonstrar o seu conceito, a sua utilização, as consequências de sua utilização de forma errada, como se desenvolve a instrução probatória no âmbito da justiça do trabalho, e as suas generalidades e peculiaridades das quais Santos elucida: "quanto à interpretação da atualidade, sabemos, também, que, nestes tempos acelerados, o tropel dos eventos desmente verdades estabelecidas e desmancha o saber."(SANTOS,2008,p. 17). O autor explica a vida no processo de globalização com auxílio da história para descrever o fato social.

\section{BIBLIOGRAFIA}

ARAÚJO, R. M. L.; RODRIGUES, D. S. Referências sobre práticas formativas em Educação Profissional: o velho travestido de novo ante o efetivamente novo. Boletim Técnico do Senac em: < http://www.bts.senac.br/index.php/bts/article/download/218/201> Acesso em 03/02/2017. BARBROOK, R. Futuros Imaginários: das máquinas pensantes à aldeia global. São Paulo, Peirópolis, 2009.

CAMPOS, F.; et al. Fundamentos da Educação a Distância, Mídias e Ambientes Virtuais. Juiz de Fora. Editar, 2007.

CEDERJ. Guia do aluno. Disponível em: < http://graduacao.cederj.edu.br/dds/arquivos/ informacoes_academicas/Guia_do_Aluno_2016_PDF__nqpp8ol9igyiwa705012016.pdf> Acesso em 03/09/2016.

CENTRO FEDERAL DE EDUCAÇÃO TECNOLÓGICA CELSO SUCKOW DA FONSECA. Disponível em: < https://www.cefet-rj.br/> Acesso em 03/09/2016.

CIAVATTA, M. A formação integrada: a escola e o trabalho como lugares de memória e de identidade. Disponível em: < http://www.uff.br/trabalhonecessario/images/TN_03/ TN3_CIAVATTA.pdf $>$ Acesso em 03/02/2017.

GANDELMAN, M. Poder e conhecimento na economia global. Rio de Janeiro: Civilização Brasileira, 2004, 317p.

INSTITUTO BRASILEIRO DE GEOGRÁFIA E ESTATÍSTICA. Disponível em: < http://

www.ibge.gov.br/home/> Acesso em 03/09/2016.

INSTITUTO PEREIRA PASSOS DA SECRETARIA DE DESENVOLVIMENTO DO MUNICÍPIO DO RIO DE JANEIRO. Disponível em: < http://www.armazemdedados.rio.rj.gov.br/> Acesso em 03/09/2016. 
LATOUR, Bruno; et al. O todo é sempre menor que as partes: um teste digital acerca das mônadas de Gabriel Tarde. Disponível em:<http://revistaseletronicas.fiamfaam.br/index.php/recicofi/ article/view/329/336>. Acesso em 03/02/2017.

MACIEL, M.L.; ALBAGLI, S. Informação, conhecimento e poder: mudança tecnológica e inovação social. Rio de Janeiro: Garamond, 2011, 332p.

MACIEL, M.L.; ALBAGLI, S; ABDO, A. H. Ciência aberta, questões abertas. Brasília, IBICT; Rio de Janeiro, UNIRIO, 2015, 312p.

MANIFESTO DAS HUMANIDADES DIGITAIS. Disponível em: < https://humanidadesdigitais.org/ manifesto-das-humanidades-digitais/>. Acesso em 03/02/2017.

MINISTÉRIO DA EDUCAÇÃO. Decreto nº 2.494, Brasília, 1998.

MINISTÉRIO DA EDUCAÇÃO. Decreto nº 5.624, Brasília, 2005.

MINISTÉRIO DA EDUCAÇÃO. Indicadores de qualidade para cursos de graduação a distância, Brasília, 2000, p.4.

MINISTÉRIO DA EDUCAÇÃO. Portaria nº4059, Brasília, 2004.

MINISTÉRIO DA EDUCAÇÃO. Portaria nº 4361, Brasília, 2004.

MOURA, Dante Henrique. Educação básica e educação profissional e tecnológica: dualidade histórica e perspectiva de integração. Disponível em: <http://www2.ifrn.edu.br/ojs/index.php/ HOLOS/article/viewFile/11/110> Acesso em 03/02/2017.

NOSELLA, Paolo. Trabalho e perspectivas de formação de trabalhadores: para além da formação politécnica. Revista Brasileira de Educação, v.12, n.34 jan./abr. 2007. Disponível em: <http:// www.scielo.br/pdf/rbedu/v12n34/a11v12> Acesso em 03/02/2017.

QGIS 2.8 wien. Sítio oficial. Disponível em: <http:www.qgis.org> Acesso em 03/02/2017.

RAMOS, J.A.S., SILVEIRA, C.S, ROIG, H.L. Desenvolvimento de um algoritmo para a determinação do fluxo e da hierarquia de canais de drenagem. Simpósio Brasileiro de Sensoriamento Remoto, v. 13, n. 2007, 2007. Disponível em: < https://scholar.google.com.br/scholar?hl=ptBR\&q=Jos\%C3\%A9+Augusto+Sapienza+Ramos+-

+Desenvolvimento+de+um+algoritmo+para+determina\%C3\%A7\%C3\%A3o+do+fluxo+ $+e+d a+h i e r a r q u i a+d e+c a n a i s+d e+d r e n a g e m \& b t n G=\& l r=>$ Acesso em: 03/09/2016.

SARTÓRIO, L. A. V.; JÚNIOR, J. R. S. A trajetória do anti-humanismo pragmatista na educação brasileira. Disponível em: < http://marxismo21.org/wp-content/uploads/2012/08/L\%C3\%BAciaV.-SART\%C3\%93RIO-Tese-Doutorado1.pdf> Acesso em 03/09/2016.

SAVIANI, D. Trabalho e educação: fundamentos ontológicos e históricos. Revista Brasileira de Educação. Disponível em: < http://www.scielo.br/pdf/rbedu/v12n34/a12v1234.pdf> Acesso em 03/02/2017.

SPIRO, Lisa. This Is Why We Fight': Defining the Values of the Digital Humanities. In: Gold, Matthew K. (editor). Debates in the Digital Humanities, Minneapolis: University of Minnesota Press, 2012. Disponível em: <http://dhdebates.gc.cuny.edu/debates/text/13>. Acesso em 03/02/2017.

TERRAVIEW 4.1.0 São José dos Campos, SP: INPE, 2010. Disponível em: < www.dpi.inpe.br/ terraview > Acesso em 03/09/2016.

UNIVERSIDADE FEDERAL FLUMINENSE. Disponível em: < http://www.uff.br/> Acesso em 03/09/2016. 
VENTURINI, Tommaso; et al. Designing Controversies and their Publics. Disponível em: < http://www.tommasoventurini.it/wp/wp-content/uploads/2014/08/Venturini-etAl_DesigningControversies-Publics.pdf>. Acesso em 03/02/2017.

\section{RESUMOS}

Este artigo tem como objetivo analisar os meios de prova no campo da justiça do trabalho. Nesse sentido, serão apresentados os meios de prova admitidos à justiça do trabalho e suas especificidades. Portanto, é necessário aprofundar o assunto e sua valorização no campo da justiça do trabalho e o modo como as presunções legais são desenvolvidas. Assim, o trabalho realizado busca apresentar as definições sobre os meios de prova na justiça do trabalho, bem como apresentar o atual entendimento doutrinário e jurisprudencial sobre o tema.

This paper aims to analyze the means of proof in the field of labor justice. In this sense, the means of evidence admitted to the labor court and its specificities will be presented. Therefore, it is necessary to deepen the subject and its valuation in the field of labor justice and the way in which legal presumptions are developed. Thus, the work carried out seeks to present the definitions on the means of evidence in labor justice, as well as present the current doctrinal and jurisprudential understanding on the subject.

Este trabajo tiene como objetivo analizar los medios de prueba en el campo de la justicia laboral. En este sentido, se presentarán los medios de prueba admitidos en el tribunal laboral y sus especificidades. Por lo tanto, es necesario profundizar el tema y su valoración en el campo de la justicia laboral y la forma en que se desarrollan las presunciones legales. Así, el trabajo realizado busca presentar las definiciones sobre los medios de evidencia en la justicia laboral, así como presentar el actual entendimiento doctrinal y jurisprudencial sobre el tema.

Cet article vise à analyser les preuves dans le domaine de la justice du travail. En ce sens, les preuves admises en justice du travail et leurs spécificités seront présentées. Par conséquent, il est nécessaire d'approfondir le sujet et son appréciation dans le domaine de la justice du travail et de la manière dont les présomptions juridiques sont développées. Ainsi, le travail effectué vise à présenter les définitions des moyens de preuve en justice du travail, ainsi qu'à présenter la compréhension doctrinale et jurisprudentielle actuelle sur le sujet.

\section{ÍNDICE}

Mots-clés: Preuve Arbitrage. Processus de travail. Réforme du travail

Keywords: Evidences. Arbitration. Labor Process. Labor Reform

Palabras claves: Evidencias. Arbitraje. Proceso Laboral. Reforma laboral

Palavras-chave: Evidências. Arbitragem. Processo de trabalho. Reforma Trabalhista

\section{AUTOR}

\section{DIANE GRACIELE GASPAR SOARES}

Especialista em Direito do Trabalho pela Universidade Estácio de Sá.

(dianegracieleadvogada@gmail.com) 